\title{
Systolic anterior motion after mitral valve repair: Is surgical intervention necessary?
}

\author{
Morgan L. Brown, MD, ${ }^{a}$ Martin D. Abel, MD, ${ }^{b}$ Roger L. Click, MD, ${ }^{\mathrm{c}}$ Ronald G. Morford, MD, ${ }^{d}$ Joseph A. Dearani, MD, \\ Thoralf M. Sundt, MD, ${ }^{a}$ Thomas A. Orszulak, MD, and Harzell V. Schaff, MD ${ }^{a}$
}

Earn CME credits at http:// cme.ctsnetjournals.org
Objective: The natural history and management of patients with systolic anterior motion after mitral valve repair are uncertain.

Methods: We performed a retrospective chart review and survey follow-up of all patients in whom systolic anterior motion developed intraoperatively after mitral valve repair.

Results: From January 1993 to December 2002, mitral valve repair was performed in 2076 patients, and in 174 cases (8.4\%) systolic anterior motion was identified on intraoperative echocardiography. These patients form the study group. Initially, patients were managed with a combination of $\beta$-blockade, vasoconstriction with phenylephrine, and/or intravascular volume expansion. Four patients had revision of repair because of persistent systolic anterior motion, and 3 additional patients had revision of repair because of mitral regurgitation from other causes. The median follow-up of the remaining 167 patients was 5.4 years (range 0-13.2 years). There were 2 late reoperations, but none were caused by systolic anterior motion or left ventricular outflow tract obstruction. Ninety percent of patients were in New York Heart Association class I, 7\% were in class II, and 3\% were in class III or IV. Echocardiograms were available for review in 93 patients at a median interval of 5.4 years (range 0.2-12.2 years); 13 patients had systolic anterior motion, and 4 patients had systolic anterior motion with left ventricular outflow tract obstruction.

Conclusions: In this experience, most cases of systolic anterior motion resolved with conservative measures including $\beta$-blockade, vasoconstriction, and fluid administration. Persistent systolic anterior motion with left ventricular outflow tract obstruction was documented in $2.3 \%$ of patients who had early systolic anterior motion, but late reoperation was not required. Furthermore, the clinical outcomes of patients with systolic anterior motion are comparable to the current norms for mitral valve repair. Ninety percent of patients were in New York Heart Association class I, 7\% were in class II, and 3\% were in class III or IV.

From the Divisions of Cardiovascular Surgery, ${ }^{\mathrm{a}}$ Anesthesiology, ${ }^{\mathrm{b}}$ and Cardiovascular Medicine, ${ }^{\mathrm{c}}$ Mayo Clinic, Rochester Minn; and Division of Cardiology, Exeter Hospital, ${ }^{\mathrm{d}}$ Exeter, $\mathrm{NH}$.

Read at the Thirty-second Annual Meeting of the Western Thoracic Surgical Association, Sun Valley, Idaho, June 21-24, 2006.

Received for publication June 19, 2006; revisions received Sept 2, 2006; accepted for publication Sept 20, 2006.

Reprint requests: Harzell V. Schaff, MD, Mayo Clinic, 200 First Street SW, Rochester, MN 55905 (E-mail: Schaff@mayo.edu).

J Thorac Cardiovasc Surg 2007;133:136-43 $0022-5223 / \$ 32.00$

Copyright () 2007 by The American Association for Thoracic Surgery

doi:10.1016/j.jtcvs.2006.09.024
$\mathrm{M}$ itral valve repair of ruptured chordae tendinae was first reported from our clinic in $1960,{ }^{1}$ and the popularity of valve repair compared with prosthetic replacement has grown because of the recognition of several desirable attributes, including the low risks of prosthetic-related hemolysis and infective endocarditis, and avoidance of long-term anticoagulation for patients in sinus rhythm. Conserving the mitral valve apparatus in mitral valve repair preserves left ventricular geometry and may reduce late mortality. ${ }^{2,3}$ Early concerns about the durability of repair have diminished with increasing evidence of excellent long-term results. ${ }^{4,5}$

The complication of systolic anterior motion (SAM) was described in early reports of mitral valve repair. ${ }^{6}$ The degree of SAM extends along a continuous spectrum from minor chordal-only SAM to its most severe form with left ventricular 


$$
\begin{aligned}
& \text { Abbreviations and Acronyms } \\
& \begin{aligned}
\text { LVOT } & =\text { left ventricular outflow tract } \\
\text { LVOTO } & =\text { left ventricular outflow tract obstruction } \\
\text { NYHA } & =\text { New York Heart Association } \\
\text { SAM } & =\text { systolic anterior motion } \\
\text { TEE } & =\text { transesophageal echocardiography }
\end{aligned}
\end{aligned}
$$

outflow tract obstruction (LVOTO). Despite numerous descriptions of preventative techniques, ${ }^{7-10}$ SAM continues to occur. The management of SAM in the operating room remains controversial with some groups advocating nonsurgical management ${ }^{11,12}$ and others proposing direct surgical correction. ${ }^{13-15}$ At our clinic, patients with SAM have in general been conservatively managed with intravenous volume loading, $\beta$-blockade, increased afterload, and limited administration of inotropic drugs. Our objectives in this study were to determine the incidence of SAM in patients with degenerative mitral valve disease, evaluate the risk of SAM with various surgical techniques, and assess the longterm outcome of nonsurgical management of SAM after mitral valve repair.

\section{Materials and Methods}

After obtaining institutional research authorization, we reviewed 2076 consecutive patients who underwent mitral valve repair between January 1993 and December 2002 at Mayo Clinic in Rochester. All study subjects were aged greater than 18 years. Patients were excluded if they had a previous diagnosis of hypertrophic obstructive cardiomyopathy, SAM due to other cause, or previous mitral valve repair or replacement. With a prospectively collected database, 174 patients were then identified who had intraoperative SAM of the mitral valve after mitral valve repair. These patients form the study cohort.

A cardiologist and/or cardiac anesthesiologist performed intraoperative transesophageal echocardiography (TEE) to evaluate the mitral valve before and after repair. SAM was identified by 2dimensional echocardiographic imaging of the mitral valve in standard views and was defined as any portion of the mitral valve leaflet or chordal structure that prolapsed into the left ventricular outflow tract (LVOT). Velocities through the LVOT were measured with pulsed and continuous-wave Doppler. The modified Bernoulli equation was used to estimate pressure gradients across the LVOT. LVOTO was considered to exist if SAM was present by 2-dimensional imaging and Doppler velocities in the LVOT were $2.0 \mathrm{~m} / \mathrm{sec}(16 \mathrm{~mm} \mathrm{Hg})$ or greater. Mitral regurgitation was graded as none-trivial, mild, moderate, moderate-severe, and severe.

All operations were performed at Mayo Clinic in Rochester, with a standard trans-sternal approach or right anterior thoracotomy. Repair techniques varied on the basis of surgeon preference and mitral valve pathology. All operative reports were reviewed to determine the type of mitral valve repair performed.

In those cases identified with intraoperative SAM, patient records and echocardiograms were further evaluated. Patients who underwent mitral valve re-repair or replacement at the time of operation or in the immediate postoperative period for any cause were examined in detail, but their long-term results were not included with the primary group who did not have further surgical procedures. Surveys designed to assess symptoms to correlate with New York Heart Association (NYHA) functional class were sent to all patients with SAM on intraoperative TEE.

\section{Results}

From 1993 to 2002, a total of 2067 patients underwent valve repair at Mayo Clinic. The cause of mitral regurgitation was determined from the surgeon's description in the operative reports, and data are summarized in Figure 1. There were 1589 patients with myxomatous disease, leaflet prolapse, or flail with ruptured chordae who were judged to be at risk of SAM. Patients who had ischemic mitral valve regurgitation or rheumatic heart disease $(n=478)$ were considered not to be at risk of SAM.

Mitral valve repairs were separated by type of annuloplasty and then further subdivided by method of leaflet repair. In most patients $(n=1545)$, a posterior flexible band was used for annuloplasty. Four patients received complete rigid rings, 12 patients received complete flexible rings, and 28 patients had either suture annuloplasty or no annuloplasty. There were 966 patients who had posterior leaflet plication or resection coupled with a flexible posterior annuloplasty band. The remaining procedures consisted of posterior annuloplasty bands alone $(n=203)$, anterior leaflet procedures $(\mathrm{n}=170)$, and complex procedures $(\mathrm{n}=$ 199). There were only 7 repairs that included a sliding annuloplasty.

Intraoperatively, 174 patients demonstrated SAM early after mitral valve repair (Table 1 ). The ages of these patients ranged from 29 to 89 years (median 62 years), and $72 \%$ were men. The mean preoperative ejection fraction was $63 \% \pm 6 \%$. Fifty-seven percent of patients had isolated mitral valve repairs. Concomitant coronary artery bypass grafting was performed in $21 \%$ of patients, and other cardiac procedures were performed in $25 \%$ of patients.

All patients in whom SAM developed had degenerative mitral valve disease, including 2 patients with active endocarditis. Posterior leaflet resection was the most common procedure performed, although anterior leaflet plications and chordal transfers, shortenings, and the addition of new chordae were also used (Table 2). Among these patients with early SAM, all had repair with a partial or complete annuloplasty ring. A flexible posterior band was placed in 172 patients (99\%), and a flexible complete ring was used in 2 patients (1\%). There were no cases of SAM in the few patients who had suture annuloplasty or rigid annuloplasty rings.

Of the 174 patients with SAM identified on intraoperative TEE, isolated SAM was found in 140 (80\%), and SAM with LVOTO was noted in $34(20 \%)$. The gradients in the 


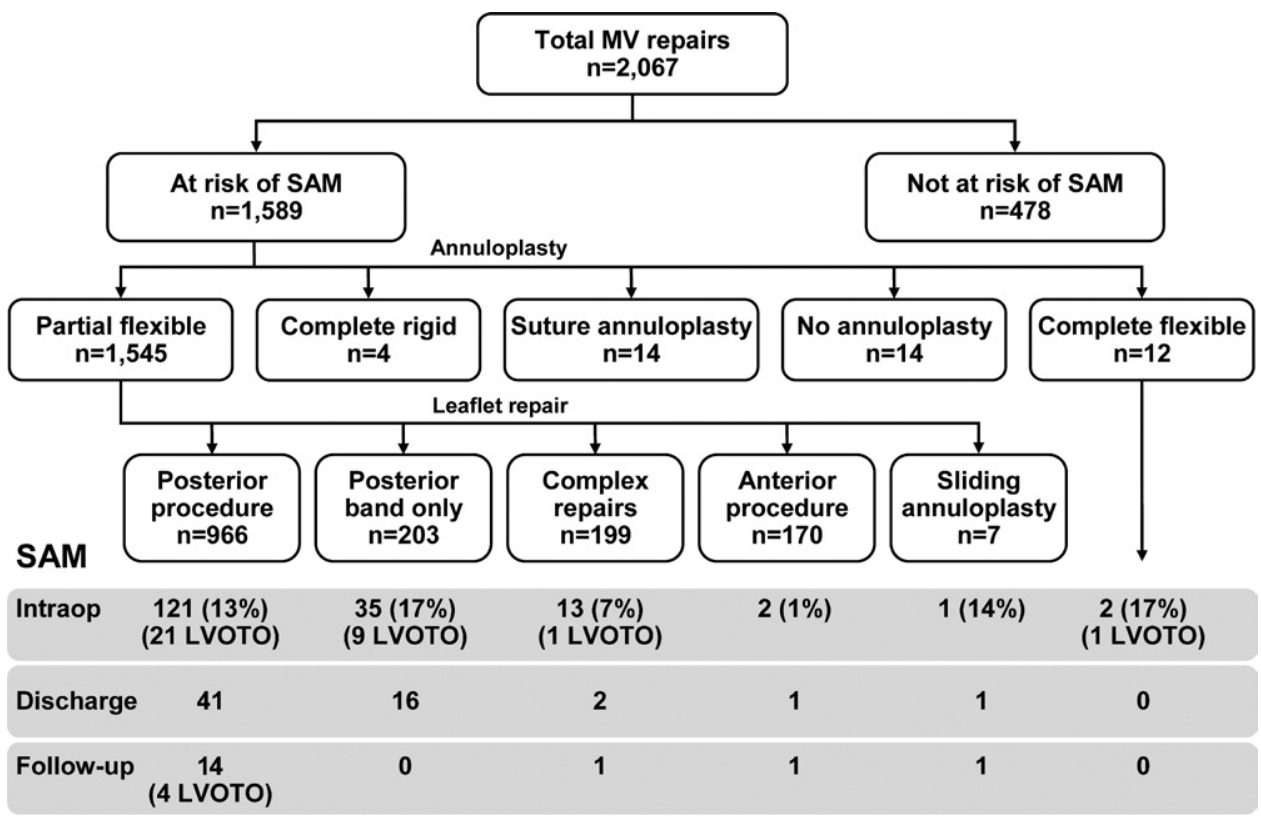

Figure 1. Patients at risk of SAM were divided according to the type of annuloplasty performed and the leaflet repair procedure. The incidence of SAM is shown. SAM, Systolic anterior motion; LVOTO, left ventricular outflow tract obstruction; $M V$, mitral valve.

LVOT were not always recorded because of the difficulty in obtaining valid Doppler velocity measurements when the angle between the ultrasound beam on TEE and the LVOT was too large ( $>30$ degrees); angle correction was not used to correct for this error. However, when recorded, the gradients ranged between 20 and $64 \mathrm{~mm} \mathrm{Hg}$.

Patients in whom SAM developed intraoperatively were managed conservatively. This included discontinuing any inotropic drugs, increasing systemic vascular resistance, augmenting intravascular volume, and administering $\beta$-blockade as tolerated.

Revision of repair or valve replacement during initial operation was undertaken in only 4 patients (Table 3 ). In 2

TABLE 1. Anatomic and functional findings in patients with intraoperative systolic anterior motion

\begin{tabular}{lrr}
\hline & No. & $\%$ \\
\hline Preoperative MR & & \\
II & 5 & 2.9 \\
III & 25 & 14.4 \\
IV & 144 & 82.8 \\
Mitral valve pathology & & \\
$\quad$ Degenerative & 174 & 100 \\
$\quad$ Anterior leaflet & 2 & 1.1 \\
$\quad$ Posterior leaflet & 90 & 51.7 \\
$\quad$ Bileaflet & 82 & 47.1
\end{tabular}

MR, Mitral regurgitation. of these 4 cases, re-repair was required because of imperfect leaflet repair and not because of SAM; 1 patient underwent resection of a residual prolapsing segment of the posterior

TABLE 2. Surgical techniques: All patients received a concomitant prosthetic annuloplasty band or ring

\begin{tabular}{lc}
\hline Type of repair & No. \\
\hline Posterior leaflet repair & $126(72 \%)$ \\
Triangular resection & 88 \\
Quadrangular resection & 11 \\
Triangular resection + chordal insertion & 13 \\
Triangular resection + Alfieri stitch & 7 \\
Triangular resection + ant plication & 3 \\
Plication & 2 \\
Plication + chordal insertion & 1 \\
Quadrangular resection + sliding annuloplasty & 1 \\
Anterior leaflet repair & $3(2 \%)$ \\
Patch & 1 \\
Plication & 2 \\
Bileaflet repair & $5(3 \%)$ \\
Post-triangular resection + anterior plication & 4 \\
Post-triangular resection + anterior plication & 1 \\
$\quad+$ chordal insertion & \\
Other & $40(23 \%)$ \\
Ring annuloplasty alone & 34 \\
Chordal insertion/transfer & 5 \\
Alfieri stitch & 1 \\
\hline
\end{tabular}


TABLE 3. Data on seven patients with systolic anterior motion who underwent revision of repair or valve replacement

\begin{tabular}{|c|c|c|c|c|c|c|c|}
\hline No. & Mitral valve pathology & Mitral valve repair & $\begin{array}{c}\text { Annuloplasty } \\
\text { type }\end{array}$ & $\begin{array}{l}\text { SAM at end of } \\
\text { operation }\end{array}$ & $\begin{array}{c}\text { Timing of } \\
\text { reoperation }\end{array}$ & Procedure performed & Reason \\
\hline 1 & Posterior prolapse & $\begin{array}{l}\text { Triangular } \\
\text { resection }+ \\
\text { posterior } \\
\text { annuloplasty }\end{array}$ & $\begin{array}{l}\text { 32-mm partial } \\
\text { flexible }\end{array}$ & NA & Intraoperative & Reinforcing sutures & $\begin{array}{c}\text { Moderate mitral } \\
\text { regurgitation }\end{array}$ \\
\hline 2 & $\begin{array}{l}\text { Anterior }+ \text { Posterior } \\
\text { prolapse }\end{array}$ & $\begin{array}{l}\text { Posterior } \\
\text { annuloplasty } \\
\text { alone }\end{array}$ & $\begin{array}{l}\text { 30-mm partial } \\
\text { flexible }\end{array}$ & NA & Intraoperative & $\begin{array}{l}\text { Posterior triangular } \\
\text { resection }\end{array}$ & $\begin{array}{l}\text { Severe mitral } \\
\text { regurgitation }\end{array}$ \\
\hline 3 & Posterior prolapse & $\begin{array}{l}\text { Posterior triangular } \\
\text { resection }+ \\
\text { posterior } \\
\text { annuloplasty }\end{array}$ & $\begin{array}{l}\text { 32-mm partial } \\
\text { flexible }\end{array}$ & NA & Intraoperative & $\begin{array}{l}\text { Removal of } \\
\text { annuloplasty ring }\end{array}$ & $\begin{array}{l}\text { SAM + elderly } \\
\text { patient }\end{array}$ \\
\hline 4 & $\begin{array}{l}\text { Posterior myxomatous } \\
\text { leaflet + annular } \\
\text { dilatation }\end{array}$ & $\begin{array}{l}\text { Posterior leaflet } \\
\text { resection }+ \\
\text { posterior } \\
\text { annuloplasty }\end{array}$ & $\begin{array}{l}\text { 34-mm partial } \\
\text { flexible }\end{array}$ & NA & Intraoperative & $\begin{array}{l}\text { Mitral valve } \\
\text { Replacement }\end{array}$ & $\begin{array}{l}\text { SAM + elderly } \\
\text { patient }\end{array}$ \\
\hline 5 & Posterior prolapse & $\begin{array}{l}\text { Posterior triangular } \\
\text { resection }+ \\
\text { posterior } \\
\text { annuloplasty }\end{array}$ & $\begin{array}{l}\text { 63-mm partial } \\
\text { flexible }\end{array}$ & None & POD 29 & $\begin{array}{l}\text { Removal of } \\
\text { annuloplasty ring }\end{array}$ & Hemolysis \\
\hline 6 & $\begin{array}{l}\text { Bileaflet myxomatous }+ \\
\text { annular dilatation }\end{array}$ & $\begin{array}{l}\text { Posterior } \\
\text { annuloplasty } \\
\text { alone }\end{array}$ & $\begin{array}{l}\text { 63-mm partial } \\
\text { flexible }\end{array}$ & None & POD 3 & $\begin{array}{l}\text { Mitral Valve } \\
\text { Replacement }\end{array}$ & $\begin{array}{l}\mathrm{SAM}+\mathrm{MV} \\
\quad \text { regurgitation }\end{array}$ \\
\hline 7 & $\begin{array}{l}\text { Myxomatous anterior }+ \\
\text { posterior } \\
\text { flail/ruptured chordae }\end{array}$ & $\begin{array}{l}\text { Posterior triangular } \\
\text { resection }+ \\
\text { posterior } \\
\text { annuloplasty }\end{array}$ & $\begin{array}{l}\text { 32-mm partial } \\
\text { flexible }\end{array}$ & None & POD 19 & $\begin{array}{l}\text { Removal of } \\
\text { annuloplasty ring }\end{array}$ & $\begin{array}{l}\text { Hemolysis + } \\
\text { SAM with } \\
\text { LVOTO }\end{array}$ \\
\hline
\end{tabular}

POD, Postoperative day; SAM, systolic anterior motion; LVOTO, left ventricular outflow tract obstruction; NA, not applicable; $M V$, mitral valve.

leaflet, and 1 patient had reinforcing sutures placed at the free edge of the incision in the posterior leaflet. In the other 2 patients, there was little improvement in SAM with medical management, and because of persistent SAM-related mitral regurgitation and the advanced age of the patients ( 81 and 83 years), the operating surgeon decided to revise the repair with removal of the band in 1 patient and mitral valve replacement in 1 patient.

In an additional 3 patients who had intraoperative SAM, reoperation was performed within the first 4 weeks postoperatively. One patient had a prosthetic ring removed because of hemolysis without evidence of SAM. A second patient, with unexpected pulmonary edema, was found to have SAM associated with moderate-severe mitral valve regurgitation that failed to diminish with aggressive $\beta$-blockade; this patient underwent subsequent replacement of the mitral valve. A third patient in whom SAM completely resolved before dismissal returned 2 weeks later with severe hemolytic anemia and recurrence of SAM coupled with an LVOTO gradient of $100 \mathrm{~mm} \mathrm{Hg}$. This patient underwent revision of repair by removal of the annuloplasty band.

The course of the remaining 167 patients who had SAM early after valve repair is shown in Figure 2. There were a total of 165 dismissal echocardiograms performed at a median interval of 5 days postoperatively (range 2-38 days). By the time of predismissal transthoracic echocardiography, SAM had resolved in 105 patients (63\%).

Of all patients who did not undergo early revision of their original mitral valve repair, 93 (57\%) had a transthoracic echocardiography after dismissal from the hospital (Table 3). Late echocardiograms were performed at a median time of 61 months (range 2.5-147 months). A total of 13 patients had SAM, and 4 patients had SAM with LVOTO. The peak LVOT velocities with the Valsalva maneuver ranged between 3.2 and $5.6 \mathrm{~m} / \mathrm{sec}$, approximately equivalent to 41 to $125 \mathrm{~mm} \mathrm{Hg}$. Hypertrophic obstructive cardiomyopathy, elderly variant, was diagnosed 7 years after mitral valve repair in the patient with the highest peak velocity. Two of these patients were asymptomatic on $\beta$-blocker therapy, and 1 patient was lost to follow-up. The mean ejection fraction at long-term follow-up was 59\% \pm $8 \%$. The durability of valve repair in patients with SAM was good, with only 2 patients requiring re-repair for severe mitral regurgitation throughout the follow-up period. It is notable that the valve regurgitation in these 2 patients was unrelated to SAM. Of the 93 patients with available echo- 


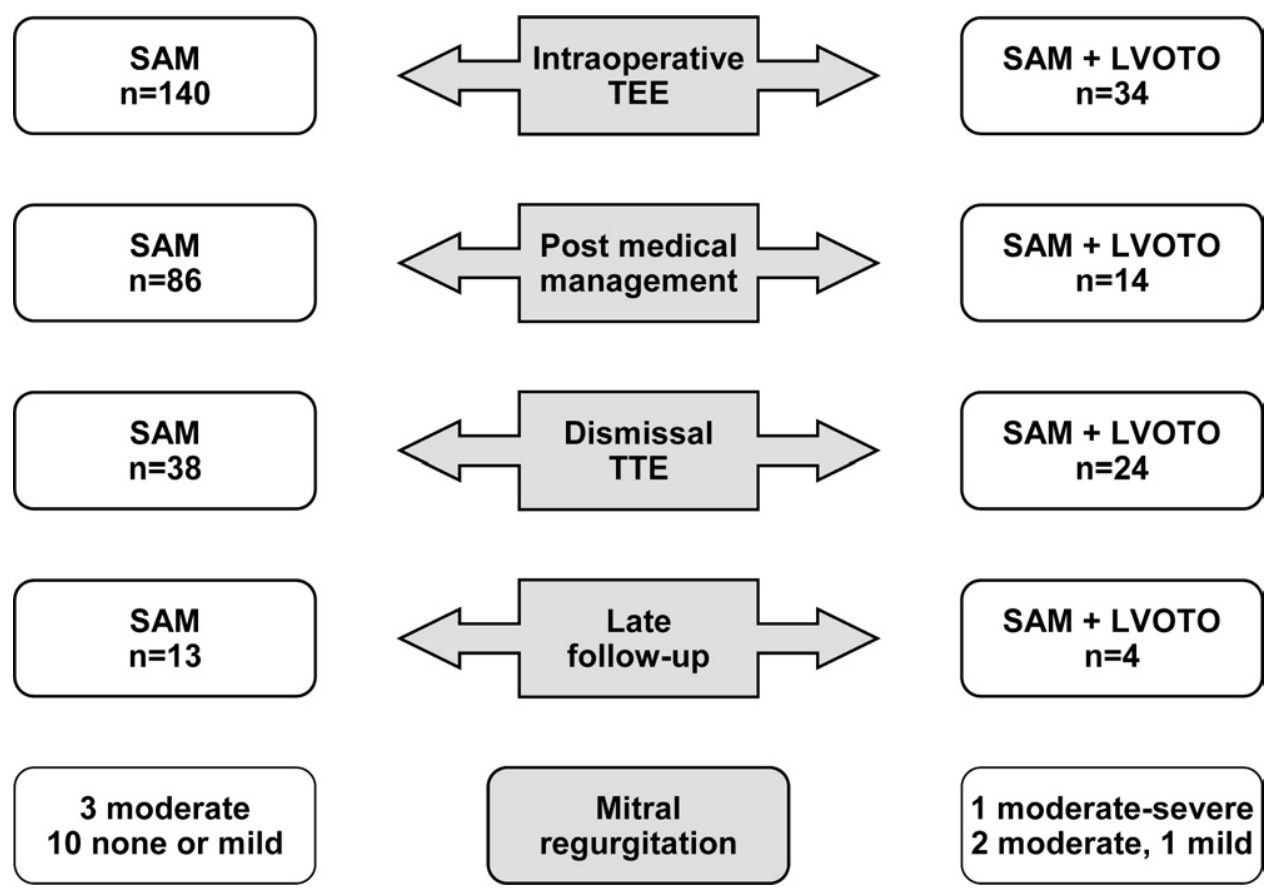

Figure 2. The incidence of SAM and LVOTO at intraoperative TEE, postmedical management, dismissal, and late follow-up. SAM, Systolic anterior motion; TEE, transesophageal echocardiography; LVOTO, left ventricular outflow tract obstruction; TTE, transthoracic echocardiography.

cardiography, $79 \%$ of patients had no or mild regurgitation, $16 \%$ had moderate regurgitation, and 5\% had moderatesevere or severe regurgitation (Table 4). Of the 5 patients with greater than moderate mitral regurgitation, 1 was elderly, and had significant comorbidities, 2 died of pneumonia, 1 was asymptomatic, and 1 was lost to follow-up.

There were no intraoperative or perioperative deaths in patients with intraoperative SAM. Fourteen patients died within the follow-up period. Causes of death included cardiac (2), cancer (4), trauma (2), pneumonia (2), stroke (1), and unknown (3). The median time to death was 5.4 years (range 0.6-11.1 years).

Follow-up was available in 139 patients at a median interval of 4.7 years (range 1.2-11.8 years). Only $34 \%$ of patients continued to report $\beta$-blocker use. Ninety percent of

TABLE 4. Severity of mitral regurgitation in patients with intraoperative systolic anterior motion

\begin{tabular}{lccc}
\hline Mitral regurgitation & End of operation & Discharge & Late follow-up \\
\hline & $\mathrm{N}=174$ & $\mathrm{~N}=165$ & $\mathrm{~N}=93$ \\
None-trivial & 107 & 112 & 44 \\
Mild & 50 & 34 & 29 \\
Moderate & 16 & 13 & 15 \\
Moderate-severe & 1 & 5 & 3 \\
Severe & 0 & 1 & 2 \\
\hline
\end{tabular}

patients were in NYHA functional class I. NYHA class II symptoms were present in $7 \%$ of patients, and $3 \%$ of patients were in NYHA class III and IV.

\section{Discussion}

Although multiple surgical techniques have been proposed to prevent SAM, it remains a problem after mitral valve repair. The overall incidence of SAM intraoperatively was $8.4 \%$ in our series, which is similar to that in previous reports $(9.1 \%$ and $7.8 \%){ }^{16,17}$ Most prior studies calculate the incidence of SAM by considering all forms of mitral valve pathology. In this study, however, we included only those patients with myxomatous disease, prolapse, or a flail leaflet with a ruptured chord. By excluding those patients with ischemic and rheumatic mitral regurgitation, the incidence of SAM increases to $11 \%$. It should be emphasized, however, that SAM resolved in most patients; at hospital dismissal, SAM was observed in 62 patients, and at last follow-up, SAM was present in only 17 patients. Consistent with previous literature, all 174 patients with SAM had degenerative mitral valve disease. ${ }^{18-20}$

Most patients at risk for SAM had posterior leaflet repair with leaflet plication or resection and a concomitant partial flexible annuloplasty ring $(\mathrm{n}=966)$. Thus, it was not surprising that the largest number of patients with SAM $(\mathrm{n}=121)$ also underwent this repair method. Although 
other repair techniques were used in smaller numbers of patients, the incidence of SAM was generally similar. It is notable that among 7 patients undergoing quadrangular resection with sliding annuloplasty, SAM developed in 1 . With triangular resection of the posterior leaflet, the most common posterior leaflet procedure in our series, sliding annuloplasty, is unnecessary. ${ }^{21}$

The occurrence of SAM was lowest among patients undergoing anterior leaflet procedures (2 patients), and this is consistent with results from other institutions where anterior leaflet pathology is corrected by limited resection ${ }^{22}$ or insertion of chordae. ${ }^{8}$

There were few complete $(n=12)$ or rigid rings $(n=4)$ in this series, so it is not possible to correlate the development of SAM with annuloplasty methods. Other reports $^{18,23,24}$ have suggested that both flexible and rigid complete rings reduce the mitro-aortic angle, thus contributing to SAM. In contrast with other studies, ${ }^{25,26}$ SAM was not observed in patients in this series who did not have prosthetic bands or ring annuloplasty.

Some authors have identified excessive reduction of annular circumference as a risk factor for SAM ${ }^{18,27}$ Certainly, annular reduction with a ring or band seems to be a contributing factor, but our data do not allow a comparison of ring size with the development of SAM. We have, in general, preferred a uniform posterior band of $6.3 \mathrm{~cm}$ for most patients. This size is predicated on the normal mitral valve annular circumference of $10 \mathrm{~cm}$ and the $2: 1$ relationship between the segment of the annulus subtended by the posterior leaflet compared with that of the anterior leaflet.

Although we could not determine which, if any, particular technique was a factor in patients' outcomes, it is clear that SAM and SAM with LVOTO can occur with a variety of repair techniques. There was no particular identifiable ring or band, rigid or flexible, or size that seemed to greatly influence the outcome. It is likely a combination of patient factors, including the cause of mitral regurgitation and hemodynamic status, and surgical factors, including both repair technique and annuloplasty, that leads to the development of SAM.

Because of the retrospective nature of this study, we cannot access surgical decisions that may have been made to attempt to "prophylactically" eliminate SAM. However, the surgical practice at our clinic has been to conservatively manage patients in whom SAM develops immediately after mitral valve repair with intravenous volume loading, $\beta$-blockade, increased cardiac afterload, and limited use of inotropic drugs. ${ }^{11,12}$ We have not commonly used methods that others have recommended to prevent SAM, including the sliding leaflet technique, ${ }^{7}$ transfer of posterior chordae to the anterior leaflet, ${ }^{8}$ anterior leaflet valvuloplasty, ${ }^{22}$ the Pomeroy procedure, ${ }^{13}$ and "edge-to-edge" repair. ${ }^{14,15}$ The rationale for not using more complex methods to prevent or treat SAM is the clinical observation that SAM improves with hemodynamic manipulation and subsequent ventricular remodeling in most patients. Indeed, among the 174 patients who manifested SAM early after mitral valve repair, only 2 had valve re-repair or replacement because of a lack of significant improvement of the degree of SAM and mitral regurgitation. Age was a factor in deciding to readdress the repair, because 2 patients were aged more than 80 years.

An additional 2 patients required reoperation within 3 weeks for postoperative SAM and LVOTO; 1 patient had associated hemolysis, and 1 patient had moderate-severe mitral regurgitation. It is important to note that SAM improved initially after repair in both patients. Both patients had severe myxomatous disease, and during reoperation 1 patient underwent successful re-repair.

There were no patients in this series who required late reoperation for SAM or SAM with LVOTO. In a recent case report by Zegdi and colleagues, ${ }^{28}$ redo mitral valve repair was performed 8 years later for SAM and LVOTO causing moderate regurgitation. The rarity of late re-repair in this study supports our clinical impression that SAM with or without LVOTO improves with time and late ventricular remodeling.

Notably, there were no perioperative or postoperative deaths among patients with SAM, and only 2 late deaths were attributable to a cardiac cause. Furthermore, on follow-up, $90 \%$ of patients were in NYHA class I. Thus, nonsurgical management was safe and yielded excellent results even among the few patients who had minor degrees of residual SAM or SAM with LVOTO.

Carpentier's group ${ }^{28}$ have expressed concerns that some repair methods designed to eliminate SAM, such as those that focus on reduction of the height anterior leaflet, are of unproven durability. Indeed, there are few late follow-up studies of such techniques. ${ }^{29}$ It should be noted that most patients in this series with prolapse of the midportion of the posterior leaflet had repair with triangular resection of the area, and this method, as in quadrangular resection with sliding annuloplasty, reduces the height of the posterior leaflet. Two patients in our series required mitral valve revision during the follow-up period, and 5 patients had moderate-severe or severe mitral valve regurgitation. This is comparable to previously reported late results of our mitral valve repairs for degenerative disease. ${ }^{30}$

Patients who have SAM after mitral valve repair need consistent cardiology follow-up and medical treatment with $\beta$-blockade and avoidance of afterload-reducing medications that could further worsen SAM and any associated mitral valve regurgitation. We recheck echocardiograms 1 month after dismissal to evaluate the degree of SAM, LVOTO, and/or mitral regurgitation. Patients who have persistent LVOTO should be followed closely until the 
obstruction resolves. Patients do not generally require lifelong $\beta$-blocker therapy. If LVOTO resolves, $\beta$-blockers may be weaned with follow-up echocardiograms 3 months later. Those who have SAM without LVOTO may be followed clinically at the discretion of a cardiologist unless there is a change in the patients' functional status or a new or changing murmur develops, at which point a repeat echocardiogram would be prudent.

SAM is an important cause of mitral regurgitation early after valve repair. Identification and proper treatment with $\beta$-blockade and avoidance of afterload-reducing medications are usually successful, and re-repair is rarely necessary. However, if medical management fails to improve mitral regurgitation, surgeons must be willing to undertake operative revision of the mitral valve repair.

The late outcomes in this series (no mortality and $90 \%$ of patients in NYHA class I at late follow-up) support the strategy of nonsurgical treatment of SAM with or without LVOTO.

\section{References}

1. McGoon DC. Repair of mitral insufficiency due to ruptured chordae tendinae. J Thorac Cardiovasc Surg. 1960;39:357-62.

2. David TE, Armstrong S, Sun Z. Left ventricular function after mitral valve surgery. J Heart Valve Dis. 1995;4(suppl 2):S175-9.

3. Enriquez-Sarano ME, Schaff HV, Orszulak TA, Tajik AJ, Bailey KR, Frye RL. Valve repair improves the outcome of surgery for mitral regurgitation. Circulation. 1995;91:1022-8.

4. Braunberger E, Deloche A, Berrebi, Abdallah F, Celestin JA, Meimoun P, et al. Very long-term results (more than 20 years) of valve repair with Carpentier's techniques in nonrheumatic mitral valve insufficiency. Circulation. 2001;104(suppl I):I8-11.

5. Mohty D, Orszulak TA, Schaff HV, Aviernios JF, Tajik JA, EnriquezSarano M. Very long-term survival and durability of mitral valve repair for mitral valve prolapse. Circulation. 2001;104:I-1.

6. Termini BA, Jackson PA, Williams CD. Systolic anterior motion of the mitral valve following annuloplasty. Vasc Surg. 1977;11:55-60.

7. Carpentier A. The sliding leaflet technique. Le Club Mitrale Newsletter. 1988;I:5.

8. Sternik L, Zehr K. Systolic anterior motion of the mitral valve after mitral valve repair: a method of prevention. Tex Heart Inst J. 2005; 32:47-9.

9. Quigley R. Prevention of systolic anterior motion after repair of the severely myxomatous mitral valve with an anterior leaflet valvuloplasty. Ann Thorac Surg. 2005;80:179-82.

10. Grossi EA, Galloway AC, Kallenbach K, Miller JS, Esposito R, Schwartz DS, et al. Early results of posterior leaflet folding plasty for mitral valve reconstruction. Ann Thorac Surg. 1998;65:1057-9.

11. Jebara VA, Mihaileanu S, Acar C. Left ventricular outflow tract obstruction after mitral valve repair. Results of the sliding leaflet technique. Circulation. 1993;88(5 Pt 2):II30-4.

12. Grossi EA, Galloway AC, Parish MA, Brizard C, Grare P, Latremouille $\mathrm{C}$, et al. Experience with twenty-eight cases of systolic anterior motion after mitral valve reconstruction by the Carpentier technique. J Thorac Cardiovasc Surg. 1992;103:466-70.

13. Raney AA, Shah PM, Joyo CI. The 'Pomeroy procedure': a new method to correct post-mitral valve repair systolic anterior motion. J Heart Valve Dis. 2001;10:307-11.

14. Gillinov AM, Smedira NG, Shiota T. Use of the Alfieri edge-to-edge technique to eliminate left ventricular outflow tract obstruction caused by mitral systolic anterior motion. Ann Thorac Surg. 2004;78:e92-3.

15. Mascagni R, Al Attar N, Lamarra M, Calvi S, Tripodi A, Mebazaa A, et al. Edge-to-edge technique to treat post-mitral-valve repair systolic anterior motion and left ventricular outflow tract obstruction. Ann Thorac Surg. 2005;79:471-4.

16. Freeman WK, Schaff HV, Khandheria BK, Oh JK, Orszulak TA, Abel $\mathrm{MD}$, et al. Intraoperative evaluation of mitral valve regurgitation and repair by transesophageal echocardiography: incidence and significance of systolic anterior motion. J Am Coll Cardiol. 1992;20:599609.

17. Morford RG, Abel MD, Schaff HV, Click RL. Systolic anterior motion of the mitral valve after surgical repair: incidence and natural history. J Am Coll Cardiol. 2003;41:503A.

18. Mihaileanu S, Marino JP, Chauvaud S, Brizard C, Grare P, Latremouille $\mathrm{C}$, et al. Left ventricular outflow obstruction after mitral valve repair (Carpentier's technique). Proposed mechanisms of disease. Circulation. 1998; (suppl I):I78-84.

19. Lee KS, Stewart WJ, Lever HM, Underwood PL, Cosgrove DM Mechanism of outflow tract obstruction causing failed mitral valve repair. Anterior displacement of leaflet coaptation. Circulation. 1993; 88(part 2):24-9.

20. Jebara VA, Mihaileanu S, Acar C, Brizard C, Grare P, Latremouille C, et al. Left ventricular outflow tract obstruction after mitral valve repair. Results of the sliding leaflet technique. Circulation. 1993;88(part 2):30-4.

21. Suri RM, Orszulak TA. Repair of mitral regurgitation due to degenerative disease. Operative Techniques in Thoracic and Cardiovascular Surgery. 2005;10:194-9.

22. Grossi EA, Steinberg BM, LeBoutillier M III, Ribacove G, Spencer FC, Galloway AC, et al. Decreasing incidence of systolic anterior motion after mitral valve reconstruction. Circulation. 1994;90(part 2):II-195-7.

23. Lopez JA, Schnee M, Gaos CM, Wilansky S. Left ventricular outflow tract obstruction and hemolytic anemia after mitral valve repair with a Duran ring. Ann Thorac Surg. 1994;58:876-8.

24. Schiavone WA, Cosgrove DM, Lever HM, Stewart WJ, Salcedo EE. Long-term follow-up of patients with left ventricular outflow tract obstruction after Carpentier Ring mitral valvuloplasty. Circulation. 1998;78(suppl I):I60-5.

25. Pasic M, Von Segesser L, Niederhauser U, Vogt P, Jenni R, Turina M Outflow tract obstruction after mitral valve repair without an annuloplasty ring. Eur J Cardiothorac Surg. 1995;9(5):283-5.

26. Aybek T, Risteski P, Miskovic A, Simon A, Dogan S, Abdel-Rahman U, et al. Seven years' experience with suture annuloplasty for mitral valve repair. J Thorac Cardiovasc Surg. 2006;131:99-106.

27. Carpentier AF, Lessana A, Relland JYM, Belli E, Mihaileanu S, Berrebi AJ, et al. The "Physio-Ring": an advanced concept in mitral valve annuloplasty. Ann Thorac Surg. 1995;60:1177-86.

28. Zegdi R, Carpentier A, Doguet F, Berrebi A, Khabbaz Z, Chauvaud S, et al. Systolic anterior motion after mitral valve repair. J Thoracic Cardiovasc Surg. 2005;130:1453-4.

29. Saunders PC, Grossi EA, Schwartz CF, Grau JB, Ribakove GH, Culliford AT, et al. Anterior leaflet resection of the mitral valve. Semin Thorac Cardiovasc Surg. 2004;16:188-93.

30. Mohty D, Orszulak TA, Schaff HV, Avierinos JF, Tajik JA, EnriquezSarano M. Very long-term survival and durability of mitral valve repair for mitral valve prolapse. Circulation. 2001;104(suppl I):I-1-7.

\section{Discussion}

Dr James I. Fann (Stanford, Calif). Dr Brown, I first want to congratulate you on an interesting and comprehensive presentation. It is always valuable to reevaluate one's experience with a difficult complication after what otherwise should be a gratifying procedure.

You and your colleagues have provided an analysis of over 2000 patients in a 10 -year period and confirmed that SAM after mitral valve repair occurs in a small fraction of patients. As you mentioned, for those at risk for SAM, mainly those with myxomatous disease and prolapse, the incidence is $11 \%$. What is of more interest and clinical challenge are those patients with outflow tract obstruction, which occurred in 34 patients, or to put it another 
way, in $2 \%$ of all patients in the series. Your approach to treatment was medical with volume infusion, $\beta$-blockade, vasoconstriction, and cessation of inotropic agents. I agree with this approach, although there are times when during the postoperative management and the patient is not doing so well that perhaps it might have been easier to have done an adjunctive procedure after establishing the diagnosis of outflow tract obstruction. Do you think a more aggressive approach should be used in the subset of patients with outflow tract obstruction?

Dr Brown. Among our patients, there were 34 who had LVOTO. The gradients that were recorded during the operating room ranged between 20 and $64 \mathrm{~mm} \mathrm{Hg}$. We found that in general, there was no trend indicating that these patients required reoperation or had any other complication. They responded well to medical management, and we do not think this is a contraindication to medical management.

Dr Fann. That is reassuring. Not only is early diagnosis of this complication and institution of treatment important, but perhaps we could determine the potential for developing SAM on the basis of preoperative or intraoperative studies. Although your analysis is retrospective, on the basis of your review of the echocardiographic data, can you comment on what findings may lead one to think that SAM is more likely? I'm referring to the utility of some proposed measurements such as the length of the coapted anterior and posterior leaflets, the ratio of the anterior and posterior leaflet lengths, the distance of the leaflet coaptation point to the septum, and the asymmetry of the anterior leaflet.

Dr Brown. Mayo Clinic published an abstract that looked at prospective echocardiographic predictors. We have not found them, as well as other published predictors, to be clinically useful. Because these patients do well with medical management, we generally do not do any preventative techniques for SAM during the original repair.

Dr Fann. When Dr Zehr was at Mayo Clinic, he described the transfer of the posterior secondary chordae to the underside of the midanterior leaflet, thereby keeping the anterior leaflet away from the outflow tract. He implied that there are patients at higher risk for SAM, specifically those with billowing, redundant, or myxomatous anterior leaflet with a near-normal-sized left ventricle and potentially hyperdynamic function. Were his patients included in your analysis, and can you give any insight into whether you think this or other adjunctive procedures, such as anterior leaflet valvuloplasty, may be of benefit?

Dr Brown. To your first question, Dr Zehr, who has unfortunately left Mayo Clinic, and all surgeons who performed mitral valve surgery within the time period of the study were included.
There were no exclusions based on surgeon. Second, in terms of the actual technique, many people have described various prophylactic surgical methods to prevent SAM. None of these have been able to show absolute prevention of SAM. In general, because of the success of our medical management, we do not routinely use these surgical treatments.

Dr Fann. In those who developed SAM, 8 patients had undergone valve repair that included placement of an Alfieri stitch at the initial procedure. This procedure, as you know, has been used to correct SAM with outflow tract obstruction. Can you explain how these patients developed SAM after placement of an Alfieri stitch at the original operation?

Dr Brown. Yes, we had 8 patients who had an Alfieri stitch who went on to develop SAM. We are aware that an Alfieri or an edge-to-edge technique has been reported in the literature as a surgical treatment for SAM once it has developed. In all of these patients, however, the Alfieri stitch was used to achieve a competent mitral valve and was not used for the purposes of SAM. We think that SAM may develop in these patients, as in our series; however, they, and all the other patients, responded well to the medical management that was instituted.

Dr Fann. What is interesting is that the majority of patients had a partial flexible annuloplasty ring, that is, in those who developed SAM, 99\% of the patients had such an initial procedure. In 2 patients who required revision, removal of the annuloplasty ring resolved the SAM. I find this interesting, and it suggests that the ring placement or sizing might have been the culprit. One recommended method of sizing is to size the anterior leaflet and not the inter-trigonal distance. Were you able to identify any particular method of ring sizing with regard to the use of a partial annuloplasty ring that could decrease the potential for SAM?

Dr Brown. I think it's important to emphasize the fact that only 2 patients required removal of the band and had resolution of their SAM. The remaining patients did well with medical management. In terms of the most common surgical technique performed at Mayo Clinic for mitral valve repair, in general and more recently, a posterior leaflet resection with an unmeasured $6.3-\mathrm{cm}$ annuloplasty band is placed.

Dr Fann. Finally, it is important to emphasize that although it is possible for late valve failure in these patients, development of SAM with outflow tract obstruction years later (as reported by others) is an unusual complication, and none of the patients required a later intervention for SAM in your series. Also, it should be reiterated that close medical follow-up is critical. 